\title{
Corrigendum to "Optimization and Corroboration of the Regulatory Pathway of p42.3 Protein in the Pathogenesis of Gastric Carcinoma”
}

\author{
Yibin Hao, ${ }^{1,2}$ Tianli Fan, ${ }^{3}$ and Kejun Nan ${ }^{1}$ \\ ${ }^{1}$ Cancer Center of the First Affiliated Hospital, College of Medicine of Xi'an Jiaotong University, Xian, Shaanxi 710061, China \\ ${ }^{2}$ Department of Oncology, Zhengzhou Central Hospital, Zhengzhou University, Zhengzhou, Henan 450007, China \\ ${ }^{3}$ Department of Pharmacology, School of Basic Medicine, Zhengzhou University, Zhengzhou, Henan 450001, China \\ Correspondence should be addressed to Kejun Nan; nankejun2013@yeah.net \\ Received 2 July 2015; Accepted 13 August 2015 \\ Copyright (c) 2015 Yibin Hao et al. This is an open access article distributed under the Creative Commons Attribution License, \\ which permits unrestricted use, distribution, and reproduction in any medium, provided the original work is properly cited.
}

In the article "Optimization and Corroboration of the Regulatory Pathway of p42.3 Protein in the Pathogenesis of Gastric Carcinoma" [1], there was an error in the author information. The affiliations for the authors were incorrectly listed. The correct author line and affiliations are shown above.

\section{References}

[1] Y. Hao, T. Fan, and K. Nan, "Optimization and corroboration of the regulatory pathway of $\mathrm{p} 42.3$ protein in the pathogenesis of gastric carcinoma," Computational and Mathematical Methods in Medicine, vol. 2015, Article ID 683679, 9 pages, 2015. 


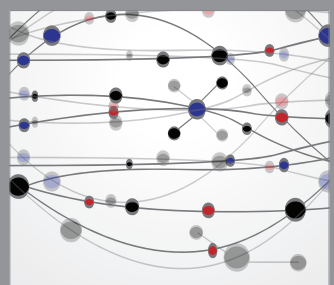

The Scientific World Journal
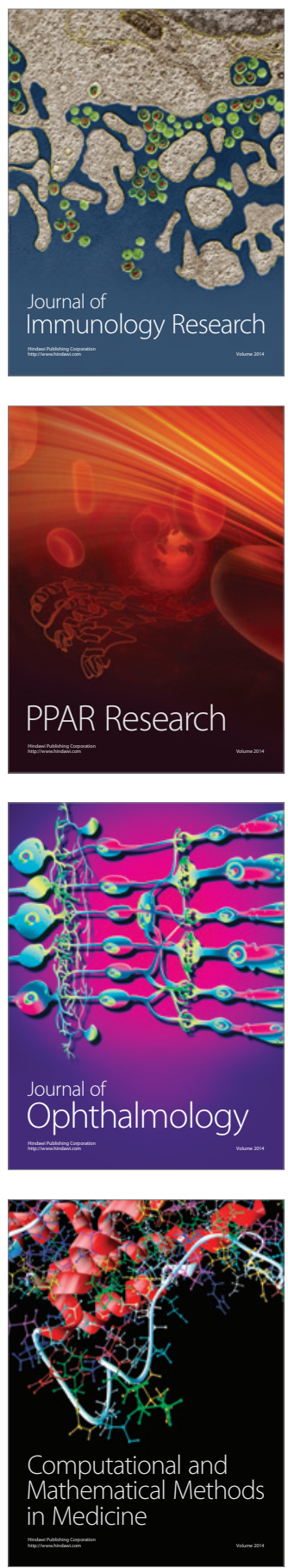

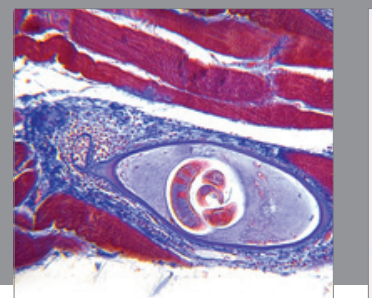

Gastroenterology

Research and Practice
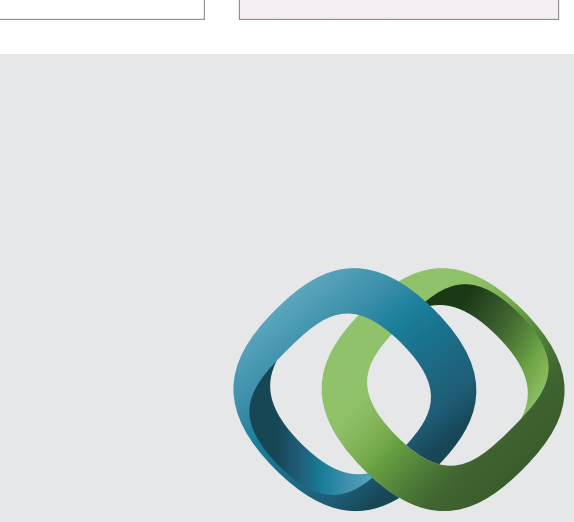

\section{Hindawi}

Submit your manuscripts at

http://www.hindawi.com
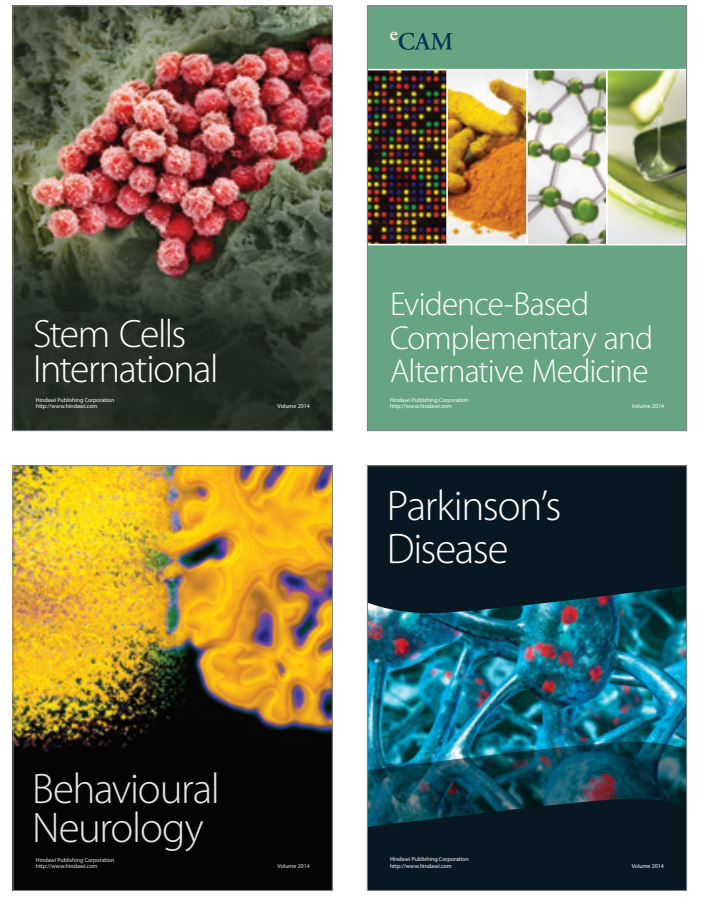
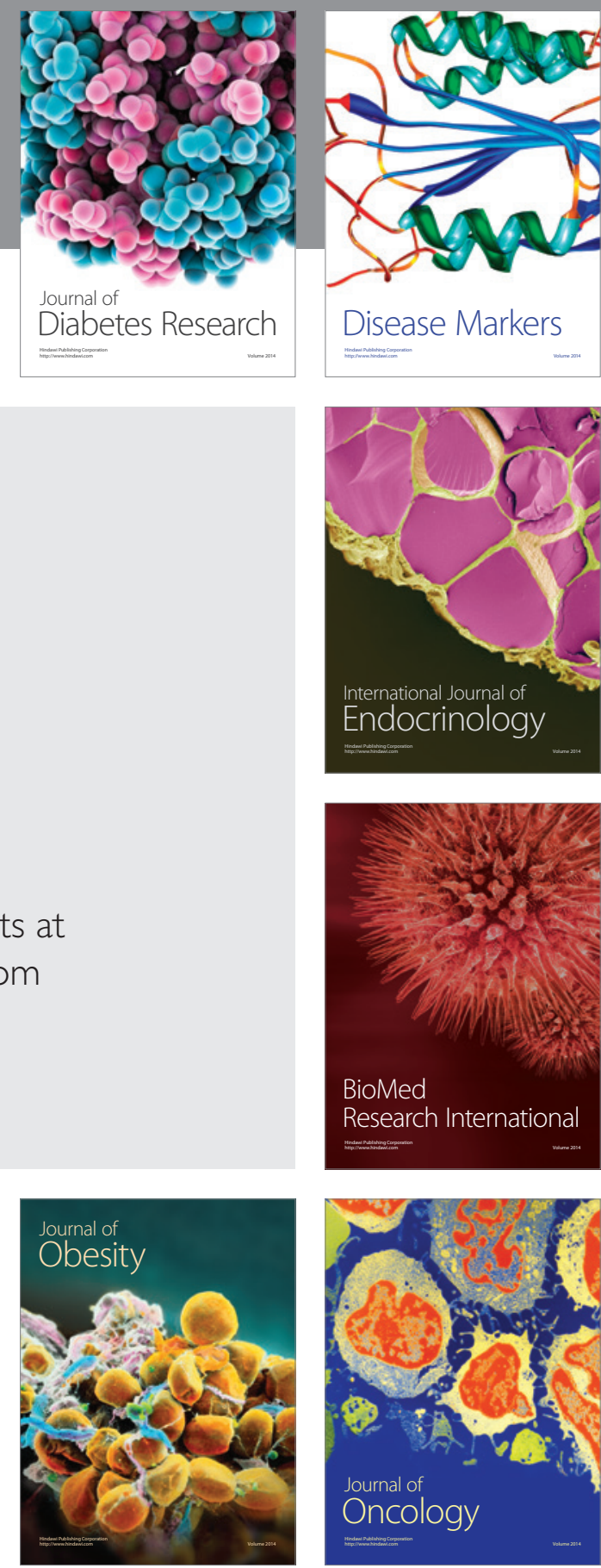

Disease Markers
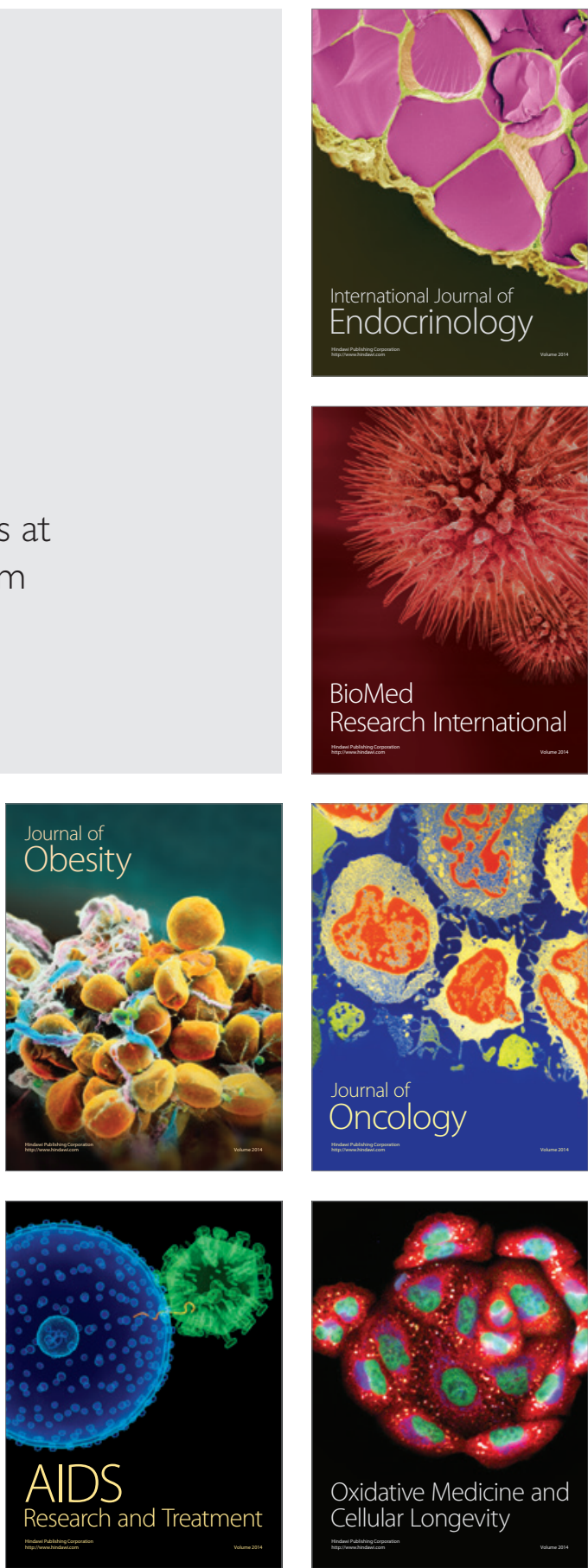